\title{
Implication of heterozygous variants in genes of the leptin-melanocortin pathway in severe obesity
}

Sophie Courbage ${ }^{1,3}$, Christine Poitou ${ }^{2,3}$, Johanne Le Beyec - Le Bihan ${ }^{4}$, Alexandra Karsenty ${ }^{1}$, Julie Lemale ${ }^{1}$, Véronique Pelloux ${ }^{3}$, Jean-Marc Lacorte ${ }^{4}$, Jean-Claude Carel $^{5}$, Nathalie Lecomte ${ }^{5}$, Caroline Storey5, Gianpaolo De Filippo5, 6, Muriel Coupaye², 7, JeanMichel Oppert², Patrick Tounian ${ }^{1,3}$, Karine Clément ${ }^{2,3}$, Béatrice Dubern ${ }^{1,3}$

1 Assistance Publique-Hôpitaux de Paris (AP-HP), Reference Centre for Rare Diseases (PRADORT, Prader-Willi Syndrome and other Rare Forms of Obesity with Eating Behavior Disorders), Pediatric Nutrition and Gastroenterology Department, Armand-Trousseau Hospital, Sorbonne University, Paris, France (SC, PT, AK, JL, BD)

${ }^{2}$ Assistance Publique-Hôpitaux de Paris (AP-HP), Reference Centre for Rare Diseases (PRADORT, Prader-Willi Syndrome and other Rare Forms of Obesity with Eating Behavior Disorders), Nutrition Department, Pitié-Salpêtrière Hospital, Paris, France. (CP, MC, JMO, KC)

${ }^{3}$ Sorbonne Université, INSERM, Nutrition and Obesities; Systemic Approaches (NutriOmics) Research Unit, Paris, France. (SC, CP, PT, VP, KC, BD)

${ }^{4}$ Assistance Publique-Hôpitaux de Paris (AP-HP), Endocrine and Oncological Biochemistry Department, Pitié-Salpêtrière Hospital, Sorbonne University, Paris, France (JLB, JML)

${ }^{5}$ Université de Paris, F-75019, Paris, France; AP-HP.Nord Université de Paris. Hôpital Universitaire Robert-Debré, Service d'Endocrinologie Diabétologie Pédiatrique F75019, Paris, France (JCC, NL, CS, GDF) 
6 Assistance Publique-Hôpitaux de Paris (AP-HP), Bicêtre Hospital, Medicine for Adolescents Department, Le Kremlin-Bicêtre, France (GDF)

7 Assistance Publique-Hôpitaux de Paris (AP-HP), Explorations Fonctionnelles Department, Louis-Mourier Hospital, Centre Intégré Nord Francilien de l'Obésité (CINFO) and Université de Paris, Centre de Recherche sur l'Inflammation, Inserm UMRS 1149, Paris, France (MC)

Corresponding author: Prof. Béatrice Dubern, Pediatric Nutrition and Gastroenterology Department, Armand-Trousseau Hospital, 26 Avenue du Dr Arnold Netter, 75012 Paris, France. E-mail: beatrice.dubern@aphp.fr. Phone +33661437291

Funding: Financial support « année-recherche » by the French Ministry of Health.

Disclosure Statement: The authors have nothing to disclose. 


\section{Abbreviations}

ACTH: Adrenocorticotropin

BMI: Body Mass Index

CRH: Cytokine Receptor Homology

DXA: Dual energy X-ray Absorptiometry

GH: Growth Hormone

LEP: Leptin

LEPR: Leptin Receptor

MC4R: Melanocortin Receptor type 4

NGS: Next-Generation Sequencing

PCSK1: Prohormone Convertase Subtilisin/Kexin type 1

POMC: Pro-opiomelanocortin

REE: Resting Energy Expenditure 


\section{Abstract}

Context. Unlike homozygous variants, the implication of heterozygous variants on the leptinmelanocortin pathway in severe obesity has not been established.

Objective. To describe the frequency, the phenotype, and the genotype-phenotype relationship for heterozygous variants in $L E P, L E P R, P O M C$, and $P C S K 1$ in severe obesity.

Methods. In this retrospective study, genotyping was performed on at least one of the LEP, LEPR, POMC, and PCSK1 genes in 1,486 probands with severe obesity (600 children, 886 adults). The phenotype was collected in 60 subjects with heterozygous variants and 16 with homozygous variants. We analyzed variant frequency, Body Mass Index (BMI), age of obesity onset, food impulsivity, and endocrine abnormalities.

Results. The frequency of subjects with homozygous variants was $1.7 \%(\mathrm{n}=26)$, and $6.7 \%$ $(n=100)$ with heterozygous variants. Adults with homozygous variants had a higher BMI (66 versus $53 \mathrm{~kg} / \mathrm{m}^{2}, \mathrm{p}=0.015$ ), an earlier onset of obesity (0.4 versus 5.4 years, $\mathrm{p}<0.001)$, more often food impulsivity (83\% versus $42 \%, \mathrm{p}=0.04)$, and endocrine abnormalities $(75 \%$ versus $26 \%, \mathrm{p}<0.01)$. The BMI was higher for subjects with highimpact heterozygous variants (61 versus $50 \mathrm{~kg} / \mathrm{m}^{2}, \mathrm{p}=0.045$ ) and those with a second heterozygous variant on the pathway (65 versus $49 \mathrm{~kg} / \mathrm{m}^{2}, \mathrm{p}<0.01$ ). In children, no significant differences were found for the age of obesity onset and BMI.

Conclusions. Heterozygous variants in $L E P, L E P R, P O M C$, and PCSK1 are frequent in severe obesity and sometimes associated with a phenotype close to that of homozygotes. These data suggest a systematic search for variants in severe early-onset obesity, to discuss therapy that targets this key pathway.

Keywords: severe early-onset obesity, leptin-melanocortin pathway 


\section{INTRODUCTION}

Genetic factors play a major role in the development of early-onset obesity, as recently demonstrated in large-scale twin studies ${ }^{1}$. Rare genetic obesities, represented by syndromic and monogenic non-syndromic obesities, are models for understanding the pathophysiological aspects of common obesity. In this field, 25 years of research led to the demonstration that the leptin-melanocortin pathway, located in the hypothalamic nuclei, is a critical pathway for the regulation of energy and body weight homeostasis. Several genes are directly involved in or regulate the leptin-melanocortin pathway. To a great extent, they include the previously described leptin $(L E P)$, leptin receptor $(L E P R)$, pro-opiomelanocortin $(P O M C)$, prohormone convertase subtilisin/kexin type 1 (PCSK1), melanocortin receptor type $3(M C 3 R)$ and type $4(M C 4 R)$ genes and, more recently, several novel genes including the regulator Melanocortin Receptor Accessory Protein 2 (MRAP2), adenylate cyclase 3 (ADCY3), Steroid Coreceptor Activator-1 (SRC-1), Semaphorin 3A-G (SEMA3A-G), PlexinA1-4 (PLXNA1-4), Neuropilin1-2 (NRP1-2) and Kinase Suppressor of Ras $2(K S R 2)^{2-4}$.

Patients with homozygous variants in LEP, LEPR, POMC and PCSK1 are characterized by an extreme phenotype with severe and early-onset obesity, hyperphagia with food seeking behavior and most often endocrine abnormalities 5 . Apart from MC4R, the phenotypic consequences of heterozygous variants are however still debated. Indeed, very few heterozygous variants in $L E P, L E P R, P O M C$ and PCSK1 have been reported, are generally associated with less severe obesity than homozygous variants and hyperphagia but have no specific phenotype ${ }^{6-12}$. Some studies however have shown, in vitro, the functional consequences of certain heterozygous variants, particularly the impaired ability of mutant $\beta$-melanocyte stimulating hormone ( $\beta$-MSH) to bind and activate MC4R signaling11,13,14 for mutations in $P O M C$, or a lower enzymatic 
activity for mutations in PCSK18,15. In addition, since some patients are carriers of heterozygous variants on several genes of this leptin-melanocortin pathway, this raises the question regarding a possible cumulative effect on the severity of obesity in these subjects with combined heterozygous variants, as such in Ayers et al ${ }^{16}$ in a British population. However, data from different populations are still lacking.

While the treatment of monogenic obesity was previously limited to leptin replacement therapy for subjects with homozygous $L E P$ variants ${ }^{17}$, novel therapeutic possibilities have recently emerged providing new avenues for treatment in these patients with monogenic obesity ${ }^{18}$. Amongst new emerging treatments in this field, setmelanotide is able to restore the melanocortin signal stimulating cyclic adenosine monophosphate (cAMP) production by an activated MC4R, in the case of homozygous mutations in $P O M C^{19}$ or $L E P R^{20}$. In patients receiving setmelanotide, a rapid decrease in hunger and significant weight loss were reported as being more pronounced in patients with POMC homozygous variants ${ }^{19,21}$.

Insofar as patients carrying heterozygous variants in LEPR, POMC and PCSK1 represent a larger population than patients carrying homozygous variants, the benefit of setmelanotide is currently unknown and needs investigation in this population. In this context, we aimed 1) to specify the frequency of $L E P, L E P R, P O M C$, and PCSK1 variants in a large cohort of patients with severe obesity, including the frequency of combined heterozygous variants, 2) to analyze the associated phenotype according to the predicted functional impact of variants, in order to highlight a genotype-phenotype relationship. 


\section{SUBJECTS AND METHODS}

Subjects

The population was comprised of 6,467 subjects $(6,347$ probands and 120 relatives), whose DNA was analyzed for at least one of the 5 LEP, LEPR, POMC, PCSK1 and MC4R genes, between 2007 and 2018 in the Functional Unit of Genetic Obesity and Dyslipidemia at Pitié-Salpêtrière Hospital (J. Le Beyec-Le Bihan). Patients were referred by the Reference Centre for Rare Diseases PRADORT (Prader-Willi Syndrome and other Rare Forms of Obesity with Eating Behavior Disorders) in the adult Nutrition Unit at PitiéSalpêtrière Hospital (K.Clément, C.Poitou, M.Coupaye, J-M.Oppert) and the pediatric Nutrition Unit at Armand-Trousseau Hospital (B.Dubern, P.Tounian, J.Lemale, A.Karsenty) in Paris, as well as by a network of French medical colleagues. The criterion for genetic screening was severe obesity defined by a BMI $>35 \mathrm{~kg} / \mathrm{m}^{2}$ in adults and a BMI Z-score $>3$ in children, with or without abnormal food behavior. As heterozygous mutations in $M C 4 R$ have already been largely described ${ }^{22}$, for the purpose of this study, we selected only subjects with available sequencing results on $L E P, L E P R, P O M C$, and/or PCSK1 genes. Patients with heterozygous combined variants including a variant in $M C 4 R$ remained selected. Hence, 1,486 probands were included in this study (Figure 1) comprising 600 children (mean age $11.1 \pm 5.0$ years) and 886 adults (mean age $32.1 \pm$ 11.5 years). DNA samples came from 76 centers, mainly from France, as well as from Tunisia, Italy, Turkey, and China. Genetic analysis was carried out as part of the care and the molecular diagnosis for children and adults suffering from severe obesity. The study was conducted in accordance with the Declaration of Helsinki and informed consent was obtained from all participating patients or their parents. 


\section{Genomic sequencing}

Genomic DNA was extracted from peripheral blood and direct sequencing (Sequencer 3730 DNA Analyzer, Applied Biosystems) was performed on at least one of the four genes: LEPR (1,265 subjects), LEP (967 subjects), POMC (618 subjects), and PCSK1 (308 subjects). The MC4R gene was also screened in 1,165 subjects of the 1,486 probands. Genotyping was then completed on other genes of the pathway (LEPR, POMC, and PCSK1) in 55 patients with heterozygous variants, using next-generation sequencing (NGS [NovaSeq 6000, Illumina, Inc]). New variants identified by NGS were subsequently confirmed by direct sequencing.

\section{Variant definition, selection and annotation}

Homozygous variants were defined as two identical variants on the same gene. Compound heterozygous variants (two different heterozygous variants on the same gene) were also considered as homozygous variants. Combined heterozygous variants were characterized as heterozygous variants on two different genes of the leptinmelanocortin pathway.

We included only rare coding variants (allele frequency $<1 \%$ ), and variants close to a splice site or the start codon. The frequent variant p.Asn221Asp in PCSK1 was also included because previous functional studies showed potential pathogenicity with a 10$30 \%$ reduction in enzymatic activity ${ }^{8,15}$. The allele frequency in the general population was determined from GnomAD (Genome Aggregation Database) ${ }^{23}$. The localization of variants identified on $L E P R$ within the receptor structure was established from the data reported by Peelman et al. and repeated by Nunziata et al 24,25 . The pathogenicity of variants was established according to functional tests from previous studies and to predicted protein consequences using the Alamut Mutation Interpretation Software 
(Interactive Biosoftware, Rouen, France) and a combination of seven in silico prediction tools for missense variants. We used HGMD (Human Genome Mutation Database), ClinVar and dbSNP to search for reported cases, genetic association studies and functional studies. The seven prediction tools used were the following: PROVEAN (Protein Variation Effect Analyzer) ${ }^{26}$, SIFT (Sorting Intolerant From Tolerant) ${ }^{27}$, PolyPhen-2 (Polymorphism Phenotyping v2) ${ }^{28}$, UMD-Predictor ${ }^{29}$, Mutation Assessor, MutationTaster ${ }^{30}$ and Align GVGD. We combined these tools for the different algorithms employed, their previous use in this topic or for their performance $29,31-33$. The results from some tools being presented in more than two classes have been grouped into binary prediction. Variants were classified as 1) "less likely damaging" if predicted "benign" and "possibly damaging" for Polyphen-2, "polymorphism" and "probable polymorphism" for UMD-Predictor, "low" and "neutral" for Mutation Assessor, "C0" to "C25" for Align GVGD and 2) "damaging" if predicted "probably pathogenic" and "pathogenic" for UMD-Predictor, "medium" and "high" for Mutation Assessor, 'C35" to “C65” for Align GVGD.

The variants were finally classified into 3 groups of functional impact:

- High: nonsense, frameshift and splice site variants, missense variants predicted "damaging" by all tools, and rare variants with conclusive functional tests.

- Moderate: missense variants predicted "damaging" by at least 4 of 7 prediction tools, and the variant PCSK1 p.Asn221Asp (frequent variant with conclusive functional tests).

- Low: missense variants predicted "less likely damaging" by at least 4 of 7 prediction tools. 


\section{Phenotypic characterization}

Data were retrospectively collected from the medical records of subjects studied or monitored at the Assistance Publique-Hôpitaux de Paris (AP-HP) in Pitié-Salpêtrière, Armand-Trousseau, Robert-Debré and Bicêtre Hospitals, and included: family weight history, age of obesity onset, anthropometric measurements (maximal weight, height, maximal BMI), eating behavior (food impulsivity, hyperphagia) based on a dietary assessment by a registered dietician, and, in adults only, body composition (body and trunk fat mass percentages) and resting energy expenditure (REE) by indirect calorimetry. The presence of co-morbidities associated with obesity was reported: obstructive sleep apnea (OSA) proven (apnea-hypopnea index > 5 per hour) or strongly suspected based on the existence of nocturnal breathing pauses, arterial hypertension (blood pressure $>130 / 80 \mathrm{mmHg}$ in adults and $>95$ th percentile in children, measured after 10 minutes of rest and every 15 minutes over an hour), insulin resistance defined by HOMA-IR ([Homeostasis Model Assessment of Insulin Resistance], glucose [mmol/L] $\mathrm{x}$ insulin $[\mathrm{mU} / \mathrm{L}] / 22.5$ ) greater than $2^{34}$, type 2 diabetes (fasting blood sugar $>7$ $\mathrm{mmol} / \mathrm{L}$ on two separate tests), and dyslipidemia including triglyceridemia $>1.7$ $\mathrm{mmol} / \mathrm{L}$ and/or total cholesterolemia $>5.2 \mathrm{mmol} / \mathrm{L}$. The characterization also included a systematic or clinically oriented endocrine assessment (leptin, IGF-1 [insulin-like growth factor-1] \pm GH [growth hormone] dynamic test, estradiol or testosterone, FSH [follicle-stimulating hormone], LH [luteinizing hormone], ACTH [adrenocorticotropin] and cortisol at 8 a.m., TSH [thyrotropin] and free T4 [thyroxine 4]), and the search for neuropsychiatric disorders (developmental delay, behavioral disorder, psychotic traits).

The age of obesity onset was defined by the age with a BMI above the IOTF 25 curve during childhood. When the BMI chart was not available, especially in adults, the age of obesity onset was estimated by interview (subjects and their parents) or pictures 
during childhood. Early-onset obesity was defined by obesity beginning before the age of 6 years. Hyperphagia was defined as an increase in food intake above the caloric needs, assessed from the calculated REE adjusted for the level of physical activity. Food impulsivity was defined as episodes of loss of food intake control. Body composition was assessed by dual energy X-ray absorptiometry (DXA [Hologic Discovery W, software version 12.6,2; Hologic Inc]) as described ${ }^{35}$. Body fat (\%) was calculated as (total fat mass $(\mathrm{kg}) /$ body weight $(\mathrm{kg})) * 100$ and trunk fat mass $(\%)$ was calculated as (trunk fat mass $(\mathrm{kg})$ / total fat mass $(\mathrm{kg})) * 100$. REE was measured by indirect calorimetry after 12 hours of overnight fasting, using an open-circuit ventilated-hood system (Deltatrac II MBM 200, Datex Instrumentarium Corp). Fasting plasma glucose and insulin concentrations were measured using the glucose oxidase method and a commercial immunoradiometric assay kit (Bi-INSULINE IRMA; CisBio International), respectively. Fasting plasma lipid levels were measured by standardized enzymatic assays (Roche Diagnostics for total cholesterol, ThermoElectron for triglycerides). Hormonal assays were performed with commercial kits available at AP-HP (standard immunoassays). Plasma leptin concentration was measured by radioimmunoassay (Linco Research, Inc) and the ratio leptin concentration $(\mathrm{ng} / \mathrm{mL})$ / fat mass $(\mathrm{kg})$ was calculated.

\section{Statistical analysis}

Continuous variables were expressed as mean and standard deviation. Due to the limited number of patients in each group, quantitative variables were analyzed with the nonparametric Mann-Whitney and Kruskal-Wallis tests. Categorical variables were tested with the Chi-square test or Fisher's exact test, when appropriate. The Spearman correlation was calculated for metric variables. All $p$-values were statistically significant if $p$ 
<.05. Statistical analyses were performed using GraphPad Prism version 8.2.0 for Windows.

\section{RESULTS}

Frequency of variants in LEP, LEPR, POMC, and PCSK1 genes

Of 1,486 probands ( 600 children and 886 adults), 126 subjects (76 children and 50 adults) carried a variant in at least one of the four genes: $L E P, L E P R, P O M C$, and PCSK1 (Table 1). Among them, $1.7 \%$ were carriers of homozygous variants $(1.5 \%$ with moderate to high predicted functional impact), and $6.7 \%$ were carriers of heterozygous variants $(3.6 \%$ with moderate to high predicted functional impact). Heterozygous variants in PCSK1 were the most common (7.4\%) but their frequency was $1.4 \%$ after excluding the frequent variant p.Asn221Asp.

In the adult subset, homozygous variants were found in $1.1 \%$ of subjects, while heterozygous variants were present in $4.5 \%$ of them $(0.8 \%$ and $2.3 \%$ respectively, for variants with moderate to high predicted functional impact).

In the children subset, the frequency of variants was higher than in adults. Homozygous variants were detected in $2.7 \%$ of children, while heterozygous variants were found in $10 \%$ of them $(2.5 \%$ and $5.5 \%$ respectively for variants with moderate to high predicted functional impact). One child was a carrier of two variants in the same LEPR gene (p.Thr699Met and p.Ser289Leu); since the variant p.Ser289Leu has a low functional impact, the child was considered as a simple heterozygous carrier in further analysis.

Twelve patients, i.e. $12 \%$ of subjects with heterozygous variants, carried a second variant on another gene of the pathway (combined heterozygous variants, Table 2). One 
adult was a carrier of two variants on the LEPR gene (p.Thr699Met and p.Asp124Gly), one of them with low functional impact (p.Asp124Gly), associated with the variant p.Asn221Asp in PCSK1. This adult was therefore considered as a combined heterozygous carrier in further analysis.

\section{Functionality of variants}

We thus identified 126 probands carrying 58 variants (Table 3, Figure 2) and, among them, 38 were found in the heterozygous state, half with low functional impact. Moreover, 17 were present in the homozygous state, including 13 with high functional impact (11 truncating mutations). Three variants with low functional impact (LEP p.Val94Met, POMC p.Asp53Gly and p.Glu214Gly) were present in both homozygous and heterozygous states.

One homozygous variant in our cohort had been previously studied in vitro (LEP p.Arg105Trp) ${ }^{36}$ as well as four heterozygous variants (POMC p.Tyr221Cys, p.Arg236Gly, and PCSK1 p.Asn221Asp studied in the heterozygous state; POMC c.-11C $>$ A studied in the homozygous state) ${ }^{8,11,13-15,37}$. Conclusive functional tests were consistent with predictions ("damaging" for 6 of 7 prediction tools), except for the frequent variant p.Asn221Asp in PCSK1 ("damaging" for only 2 prediction tools, PROVEAN and UMDPredictor). In $L E P R$, the 8 missense variants located in the cytokine receptor homology (CRH) II and the immunoglobulin-like (Ig) domains, which are LEP interacting sites ${ }^{25}$, were predicted to have moderate to high functional impact, while the 5 missense variants located in the CRH I domain were predicted to have low functional impact.

Regarding combined heterozygous variants, the most frequent was p.Asn221Asp in PCSK1 (Table 2) whose frequency is 3.8\% in the general population ${ }^{23}$. Nevertheless, it has been reported to be associated with obesity and in vitro functional studies have 
shown a decrease in enzyme activity of $10.4 \%$ to $30 \% 8,15,38$. Likewise, the functionality of the combined variant p.Ser58Cys in MC4R has been demonstrated in vitro ${ }^{39}$. Although the variant p.Val94Met in $L E P$ was predicted as "less likely damaging", a study of 2,129 African-Americans showed evidence of a contribution to obesity ${ }^{40}$. The pathogenicity of the rare variant p.Asp53Gly in POMC has not been reported, however it was carried herein in the homozygous state by a subject with an extreme phenotype, and a slight increase in prevalence was described among obese children in our previous study 6 . Although the functional impact of the variant c.1196+6del in PCSK1 in still unclear, it is located close to a splice site and was included as a combined heterozygous variant.

\section{Associated phenotypes}

Among 126 probands, the phenotype was retrospectively collected from 60 subjects with heterozygous variants (29 children, 31 adults) including 8 with combined heterozygous variants ( 2 children, 6 adults), and 16 subjects with homozygous variants (4 children, 12 adults). The most commonly represented gene with variant was LEPR. The main phenotypic characteristics are depicted in Table 4.

In the children subset, the phenotype of patients with heterozygous variants was similar to that of patients with homozygous variants: the mean age of obesity onset was before 3 years with a mean BMI Z-score $>6$ in both groups. However, food impulsivity and endocrine abnormalities were more frequent in children carrying homozygous variants. Metabolic complications (insulin resistance, arterial hypertension, dyslipidemia) were as prevalent in both groups. Parental obesity was higher among children carrying heterozygous variants than among children carrying homozygous variants. 
In the adult subset, subjects with heterozygous variants had obesity beginning before the age of 6 years in half of the cases, and most often hyperphagia. Subjects carrying homozygous variants had more severe obesity with earlier-onset compared to subjects carrying heterozygous variants, as well as more frequent food impulsivity episodes and central endocrine abnormalities. In contrast, metabolic complications were less prevalent than in subjects with heterozygous variants, in particular arterial hypertension, and insulin resistance markers. In addition, patients with homozygous variants had a lower truncal distribution of adipose tissue.

We found an association between the age of obesity onset and the severity of obesity. In children with homozygous and heterozygous variants, the younger the age of obesity onset, the higher the BMI was (Spearman $r=-0.396, p=.025$, Figure 3). In adults, due to the lack of precise data about the age of obesity onset, we were not able to replicate this finding. However, we compared the BMI according to the age of obesity onset ( $<$ or $>$ to 6 years of age) and found that subjects with age of obesity onset before 6 years had a significantly higher BMI $\left(62.1 \pm 15.4 \mathrm{~kg} / \mathrm{m}^{2}\right.$ versus $\left.47.7 \pm 9.9 \mathrm{~kg} / \mathrm{m}^{2}, \mathrm{p}<.01\right)$.

Importantly, endocrine deficiencies were found in $15 \%$ of subjects with heterozygous variants. Hypogonadotropic hypogonadism was the most common deficiency in adults, and mainly associated with variants in LEPR (Table 5). Moreover, one patient carrying combined heterozygous variants in POMC (p.Tyr221Cys) and PCSK1 (p.Asn221Asp) had hypogonadism, ACTH, and GH deficiencies. Interestingly, two children with PCSK1 heterozygous variants (p.Leu22Pro and p.Ser24Metfs*73) had unspecified chronic diarrhea, while one child carrier of a homozygous variant in PCSK1 had required parenteral nutrition for neonatal diarrhea.

Other syndromic features such as neurodevelopmental anomalies (walking, speech, or mental delays, neonatal hypotonia) were reported in 13 heterozygous 
patients and could be linked to another associated genetic or medical condition in only 3 cases (duplication 22q11, stroke, neonatal encephalopathy). Psychiatric disorders with behavioral impulsivity, hetero-aggressivity or psychotic traits were observed in $15 \%$ of patients carrying heterozygous variants and $19 \%$ of patients with homozygous variants. These were more frequent in cases with variants in POMC (40\%) or PCSK1 (29\%) rather than $L E P R(12 \%)$, and were associated with food impulsivity in two-thirds of cases.

Interestingly, two sisters with the same combined heterozygous genotype (MC4R p.Ser58Cys and LEPR p.Thr699Met) had a different phenotype for the age of obesity onset (3.6 versus 15.0 years), severity of obesity (BMI 58 versus $48 \mathrm{~kg} / \mathrm{m}^{2}$ ) and eating behavior (impulsivity was noted in the first one only).

\section{Association between phenotypes and functional impact of variants}

In children, small population sizes (only one high-impact heterozygous variant) did not allow for statistical comparison.

In adults with heterozygous variants, 2 patients with unknown impact variants and 1 with a combined variant found by NGS but not detected by direct sequencing were excluded. The BMI of patients carrying heterozygous variants was significantly higher for high functional impact variants compared to low to moderate impact variants (BMI $60.8 \pm 9.5 \mathrm{~kg} / \mathrm{m}^{2}$ versus $50 \pm 11.9 \mathrm{~kg} / \mathrm{m}^{2}, \mathrm{p}=.045$, Figure 4). In the same way, earlyonset obesity ( $<6$ years of age) tended to be more frequent for high functional impact variants, even though not statistically significant ( $80 \%$ versus $48 \%, \mathrm{p}=.33$ ), as well as food impulsivity episodes ( $80 \%$ versus $35 \%, \mathrm{p}=.13$ ).

In adults with homozygous variants, no statistical difference was found for BMI according to variant functionality (BMI $68.5 \pm 14.1 \mathrm{~kg} / \mathrm{m}^{2}$ for high-impact variants versus $60.7 \pm 19.5 \mathrm{~kg} / \mathrm{m}^{2}$ for low to moderate-impact variants, $\mathrm{p}=.57$ ). 
Combined effect of heterozygous variants on phenotype

Only subjects with a single heterozygous variant who were sequenced on the five genes (LEP, LEPR, POMC, PCSK1 and MC4R) were considered for this analysis. The statistical analysis was not performed in children due to the small number (2 with combined heterozygous variants). The mean BMI Z-score in the children subset was 6.2 \pm 2.0 for heterozygous variants, $6.2 \pm 0.5$ for combined heterozygous variants, and $7.2 \pm$ 3.5 for homozygous variants.

The BMI of six adults with combined heterozygous variants was compared to 20 subjects with a single heterozygous variant and 12 subjects with homozygous variants. We observed that the BMI of patients with combined heterozygous variants was significantly higher than the BMI of patients with a single heterozygous variant (BMI $65.2 \pm 13.2 \mathrm{~kg} / \mathrm{m}^{2}$ versus $49.0 \pm 9.1 \mathrm{~kg} / \mathrm{m}^{2}, \mathrm{p}<.01$ ) and similar to the BMI of patients with homozygous variants (BMI $65.9 \pm 15.7 \mathrm{~kg} / \mathrm{m}^{2}$ ), Figure 5 .

It should be noted that the frequency of high functional impact variants was comparable between children and adults with a single heterozygous variant ( $6 \%$ versus $10 \%$ respectively). However, adults with combined heterozygous variants more frequently had a high impact variant (50\%) than adults with a single heterozygous variant (10\%), and children with combined heterozygous variants $(n=0)$.

\section{DISCUSSION}

\section{Principal findings}

In the last 15 years, we prospectively screened a large cohort of children and adults with severe obesity monitored in university hospitals allowing to determinate that the frequency of heterozygous variants in $L E P, L E P R, P O M C$ and PCSK1 genes was $6.7 \%$, with $3.6 \%$ of variants with moderate to high predicted functional impact. In 
children, this frequency was higher: $10 \%$, with $5.5 \%$ of variants with moderate to high predicted functional impact. Most importantly, in patients carrying high functional impact variants or variants on several genes of the pathway, we reported a clinical phenotype similar to that of subjects with homozygous variants, with severe obesity and sometimes early-onset obesity and endocrine abnormalities. Highlighting a genotypephenotype relationship, our results suggest the implication of heterozygous variants in the development of severe obesity, and paves the way for systematic genetic screening in this candidate population to benefit from new pharmaceutical therapy.

\section{Comparison with other studies}

The frequency of detected variants was higher in our study than those previously described for heterozygous variants in $\operatorname{LEP}(0.1-0.8 \%)^{33,41}, \operatorname{LEPR}(1.9-3 \%)^{33,42}, P O M C$ $(1.2-2.3 \%)^{33,43}$ and PCSK1 $(0.5-1.4 \%)^{33,43,44}$, also depended on the population screened. It is important to note that most studies focused on only one of the 4 genes involved in the leptin-melanocortin pathway. Increased frequency in our population may be due to the mode of subjects recruitment, mainly in centers specialized in the management of severe obesity, as well as ethnicity since some variants in $L E P, L E P R$, and POMC are more frequent among people of African origin ${ }^{23}$. The enrichment of pediatric recruitment also selected patients with early-onset severe obesity, which was highlighted by an increased detection of pathogenic variants in this population.

The severe obesity phenotype observed in subjects with heterozygous variants, especially for high-impact variants, as well as frequent endocrine or neurodevelopmental abnormalities had not been reported until then. Indeed, in a few reports, subjects with heterozygous variants generally displayed early-onset non-severe

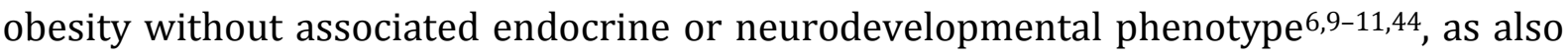
seen in subjects with $M C 4 R$ variants ${ }^{7,45}$. Endocrine abnormalities, found in one-quarter 
of adults with heterozygous variants, were mainly hypogonadotropic hypogonadism. The role of leptin in pubertal development is well recognized although the mechanisms are poorly understood. Because these hormonal deficiencies could appear late in adolescence and spontaneously be corrected in adulthood ${ }^{46}$, diagnosis may be difficult. It was previously demonstrated that subjects with homozygous variants are described to have a more severe phenotype with early-onset and more severe obesity, food impulsivity and endocrine abnormalities, $7,9,47,48$. However, we show here that some carriers of heterozygous variants with potential high functional impact could display a clinical phenotype similar to subjects with homozygous variants.

In contrast, the metabolic phenotype (arterial hypertension, insulin resistance markers) was less severe in subjects with homozygous variants than subjects with heterozygous variants. This relative protection from metabolic injury that was previously observed in patients with leptin deficiency ${ }^{46}$ may be related to a specific fat mass patterning with increased subcutaneous adipose tissue and decreased visceral adipose tissue. As such, carriers of homozygous variants showed a lower proportion of DXA-assessed trunk fat in agreement with gynoid distribution of fat mass. Thus, despite a severe obesity phenotype, this peculiar distribution of adipose tissue could lead to a favorable cardiometabolic profile. In children, metabolic complications were equivalent in both populations with homozygous and heterozygous variants and identical to those observed in obese pediatric cohorts ${ }^{49,50}$.

No studies examining the phenotype of children carrying heterozygous and homozygous variants in genes of the leptin-melanocortin pathway have been reported to date. As seen in adults, we found in children that carriers of heterozygous variants had a phenotype comparable to carriers of homozygous variants for the severity and precocity of obesity. Knowing that these young patients were recruited based on a 
severe obesity phenotype, the clinical expression of these variants early in life may nevertheless indicate a marked impact on future corpulence at adult age, as also suggested by the evidence of a negative correlation between age of obesity onset and BMI. Moreover, the ability to better control food intake in adulthood could contribute to the less severe phenotype observed in adults than in children. Nevertheless, we cannot exclude that other genes involved in the control of energy homeostasis may be implicated in the development of severe obesity before the age of 6 years. Indeed, recent studies have described new involved genes, as MRAP2 or $A D C Y 3^{3,51 .}$

Here we showed a significant genotype-phenotype relationship in heterozygous forms of monogenic obesity. Indeed, we found that individuals with high-impact heterozygous variants exhibit higher BMI than subjects carrying heterozygous variants with lower predicted functional impact. The same trend was observed for food impulsivity as well as early-onset obesity, albeit not significantly. Although one study covering phenotypes and functional tests related to $L E P R$ variants in the literature failed to detect an obvious genotype-phenotype relationship ${ }^{25}$, previous studies on $M C 4 R$ variants had shown that patients with complete loss of function and intracellular receptor retention had a more severe and earlier obesity 7,45 . Furthermore, the evidence of variants with high to moderate predicted functional impact located within the leptin interaction domains suggests the relevance of variant localization on $L E P R$. In addition, the more severe obesity phenotype observed in carriers of variants on two genes of the pathway compared to carriers of a single heterozygous variant indicates a cumulative effect on BMI. This effect has recently been suggested by Ayers et al., with the most severe obesity showing a higher proportion of combined variants in $L E P R$ and POMC, involving the variant p.Asn221Asp in PCSK1 ${ }^{16}$. However, in our cohort, variants with high functional impact were more frequently detected in subjects with combined 
heterozygous variants and homozygous variants than in subjects with a single heterozygous variant, suggesting that the functionality of variants may also be implicated in the phenotype.

Our results may suggest the contribution of some heterozygous variants on these genes to polygenic forms of obesity, and thus the likelihood of these results being applied to a wider population. First, the less severe phenotype of subjects with heterozygous variants may indicate a codominant mode of inheritance, as previously mentioned for $M C 4 R$ mutations ${ }^{7}$. The evidence of a cumulative effect on BMI in the case of two combined heterozygous variants in the pathway was also supporting this hypothesis, as already suggested by Ayers et $\mathrm{al}^{16}$. Furthermore, the more frequent parental obesity in children with heterozygous variants than in children with homozygous variants could be explained by a polygenic contribution of heterozygous variants to obesity, and a codominant mode of expression. Finally, some studies, in particular linkage studies, have shown the implication of some variants on $L E P, L E P R$, POMC, and PCSK1 in the genetic predisposition to obesity $8,16,40$.

However, our results also suggest a dominant negative effect of some heterozygous variants. Indeed, adults carrying high-impact heterozygous variants had a similar BMI to those carrying homozygous variants. Thus, the initial description of a recessive autosomal transmission of variants in $L E P R$ or $L E P^{5}$ may be jeopardized by our findings, such as deleterious variants in novel genes as MRAP2 or SEMA3A-G are mainly heterozygous variants and are associated with early-onset obesity 4,51 .

The existence of healthy relatives with the same variants in control individuals (reported in the literature, for POMC variants p.Glu214Gly, p.Asp53Gly, p.Ala195Thr, and p.Tyr221Cys ${ }^{6,13}$ ) indicates an incomplete penetrance, as already shown in nonobese subjects with functional heterozygous mutations in $M C 4 R^{39}$. Moreover, the 
variability of phenotypes for the same variant suggests a variable expressivity of heterozygous variants.

\section{Weaknesses and strengths of the study}

The main limitation of the study is the lack of comparison between subjects carrying variants and subjects for whom sequencing was negative. Another major limit is the use of software tools for the functional characterization of variants, with only a few heterozygous variants characterized with functional assays in currently available studies. The retrospective collection of phenotypic data, and their heterogeneity linked to the multicentric recruitment are other concerns. Furthermore, our study contains a selection bias as we included patients with the most severe obesity, who were referred to care in specialized centers and followed at university hospitals. Despite these limits, it is the first report to specifically describe the phenotype of subjects with heterozygous variants, to highlight endocrine abnormalities in subjects with heterozygous variants, and to suggest a genotype-phenotype relationship in these monogenic obesities, particularly the cumulative effect of several variants on the phenotype.

\section{Conclusions}

Heterozygous variants in the main genes of the melanocortin pathway ( $L E P$, LEPR, PCSK1 and POMC) are more frequent than previously reported in a population with severe obesity recruited in French university hospitals, and especially in children. The phenotype of these subjects with heterozygous variants may be characterized by severe and early-onset obesity with food impulsivity, endocrine or neurodevelopmental abnormalities, thus similar to the phenotype of subjects with homozygous variants. We highlight herein a genotype-phenotype relationship in these heterozygous forms, based on the association between the functional impact of variants and BMI, and the 
cumulative effect of combined heterozygous variants on the BMI. The study of a larger population is necessary to confirm these results and to show a strong association between the functional impact of variants and other clinical features. Therefore, these results suggest that heterozygous variants in genes of the leptin-melanocortin pathway still need to be suspected in subjects with severe obesity, or a phenotype resembling syndromic and monogenic homozygous obesity. They should prompt clinicians to diagnose such obesities, notably before bariatric surgery, in order to indicate instead a therapy that targets the melanocortin pathway ${ }^{18-20,22}$. 
Acknowledgments: We thank the patients and their families, caregivers, and prescribing physicians. We also thank several supports in the last 15 years obtained from previous "Clinical research programs" (PHRC, CRC) under the promotion of Assistance Publique-Hôpitaux de Paris that enabled the creation of a patient register to gather information about these monogenic disorders.

Authors contributions: The authors' responsibilities were as follows: $\mathrm{BD}$ and $\mathrm{CP}$ created and supervised the study from a cohort initiated by KC and PT in early 2000; BD, CP, and SC designed the study; SC and JLB collected the data; JLB and SC performed the genetic analyses; SC performed the statistical analyses; SC, $\mathrm{BD}, \mathrm{CP}$, and $\mathrm{KC}$ interpreted the data; SC wrote the first draft of the manuscript; $\mathrm{BD}, \mathrm{CP}, \mathrm{KC}$, and PT contributed to the manuscript writing for important intellectual content; BD, CP, KC, PT, AK, JL, JCC, NL, CS, MC, GD, and JMO participated in patient care. All authors revised and contributed to the final manuscript.

Data sharing: Some or all datasets generated during and/or analyzed during the current study are not publicly available but are available from the corresponding author on reasonable request. 


\section{REFERENCES}

1. Silventoinen K, Jelenkovic A, Sund R, et al. Genetic and environmental effects on body mass index from infancy to the onset of adulthood: an individual-based pooled analysis of 45 twin cohorts participating in the COllaborative project of Development of Anthropometrical measures in Twins (CODATwins) study. Am J Clin Nutr. 2016;104(2):371-379.

2. Van Der Klaauw AA, Farooqi IS. The hunger genes: Pathways to obesity. Cell. 2015;161(1):119-132.

3. Saeed S, Bonnefond A, Tamanini F, et al. Loss-of-function mutations in ADCY3 cause monogenic severe obesity. Nat Genet. 2018;50(2):175-179.

4. van der Klaauw AA, Croizier S, Mendes de Oliveira E, et al. Human Semaphorin 3 Variants Link Melanocortin Circuit Development and Energy Balance. Cell. 2019;176(4):729-742.e18.

5. Huvenne H, Dubern B, Clément K, Poitou C. Rare Genetic Forms of Obesity: Clinical Approach and Current Treatments in 2016. Obes Facts. 2016;9(3):158-173.

6. Dubern B, Lubrano-Berthelier C, Mencarelli M, et al. Mutational Analysis of the Pro-opiomelanocortin Gene in French Obese Children Led to the Identification of a Novel Deleterious Heterozygous Mutation Located in the $\alpha$-Melanocyte Stimulating Hormone Domain. Pediatr Res. 2008;63(2):211-216.

7. Farooqi IS, Keogh JM, Yeo GSH, Lank EJ, Cheetham T, O’Rahilly S. Clinical Spectrum of Obesity and Mutations in the Melanocortin 4 Receptor Gene. N Engl J Med. 2003;348(12):1085-1095.

8. Benzinou M, Creemers JWM, Choquet H, et al. Common nonsynonymous variants in PCSK1 confer risk of obesity. Nat Genet. 2008;40(8):943-945.

9. Huvenne H, Le Beyec J, Pépin D, et al. Seven Novel Deleterious LEPR Mutations Found in Early-Onset Obesity: a $\Delta$ Exon6-8 Shared by Subjects From Reunion Island, France, Suggests a Founder Effect. $J$ Clin Endocrinol Metab. 2015;100(5):E757-E766.

10. Philippe J, Stijnen P, Meyre D, et al. A nonsense loss-of-function mutation in PCSK1 contributes to dominantly inherited human obesity. Int J Obes (Lond). 2015;39(2):295-302.

11. Challis BG, Pritchard LE, Creemers JWM, et al. A missense mutation disrupting a dibasic prohormone processing site in pro-opiomelanocortin (POMC) increases susceptibility to early-onset obesity through a novel molecular mechanism. Hum Mol Genet. 2002;11(17):1997-2004.

12. Farooqi IS, Keogh JM, Kamath S, et al. Partial leptin deficiency and human adiposity. Nature. 2001;414(6859):34-35.

13. Lee YS, Challis BG, Thompson DA, et al. A POMC variant implicates $\beta$-melanocyte-stimulating 
hormone in the control of human energy balance. Cell Metab. 2006;3(2):135-140.

14. Biebermann H, Castañeda TR, van Landeghem F, et al. A role for $\beta$-melanocyte-stimulating hormone in human body-weight regulation. Cell Metab. 2006;3(2):141-146.

15. Blanco EH, Ramos-Molina B, Lindberg I. Revisiting PC1/3 Mutants: Dominant-Negative Effect of Endoplasmic Reticulum-Retained Mutants. Endocrinology. 2015;156(10):3625-3637.

16. Ayers KL, Glicksberg BS, Garfield AS, et al. Melanocortin 4 Receptor Pathway Dysfunction in Obesity: Patient Stratification Aimed at MC4R Agonist Treatment. J Clin Endocrinol Metab. 2018;103(7):26012612.

17. Farooqi IS, Matarese G, Lord GM, et al. Beneficial effects of leptin on obesity, T cell hyporesponsiveness, and neuroendocrine/metabolic dysfunction of human congenital leptin deficiency. $J$ Clin Invest. 2002;110(8):1093-1103.

18. Roubert P, Dubern B, Plas P, et al. Novel pharmacological MC4R agonists can efficiently activate mutated MC4R from obese patient with impaired endogenous agonist response. J Endocrinol. 2010;207(2):177-183.

19. Kühnen P, Clément K, Wiegand S, et al. Proopiomelanocortin Deficiency Treated with a Melanocortin-4 Receptor Agonist. N Engl J Med. 2016;375(3):240-246.

20. Clément K, Biebermann H, Farooqi IS, et al. MC4R agonism promotes durable weight loss in patients with leptin receptor deficiency. Nat Med. 2018;24(5):551-555.

21. Clément K, van den Akker E, Argente J, et al. Efficacy and safety of setmelanotide, an MC4R agonist, in individuals with severe obesity due to LEPR or POMC deficiency: single-arm, open-label, multicentre, phase 3 trials. Lancet Diabetes Endocrinol. 2020;8(12).

22. Collet T-H, Dubern B, Mokrosinski J, et al. Evaluation of a melanocortin-4 receptor (MC4R) agonist (Setmelanotide) in MC4R deficiency. Mol Metab. 2017;6(10):1321-1329.

23. Karczewski KJ, Francioli LC, Tiao G, et al. Variation across 141,456 human exomes and genomes reveals the spectrum of loss-of-function intolerance across human protein-coding genes. bioRxiv. January 2019:531210.

24. Peelman F, Zabeau L, Moharana K, Savvides SN, Tavernier J. Insights into signaling assemblies of the leptin receptor. J Endocrinol. 2014;223(1):T9-T23.

25. Nunziata A, Funcke J-B, Borck G, et al. Functional and Phenotypic Characteristics of Human Leptin Receptor Mutations. J Endocr Soc. 2019;3(1):27-41. 
26. Choi Y, Chan AP. PROVEAN web server: a tool to predict the functional effect of amino acid substitutions and indels. Bioinformatics. 2015;31(16):2745-2747.

27. Ng PC, Henikoff S. SIFT: predicting amino acid changes that affect protein function. Nucleic Acids Res. 2003;31(13):3812-3814.

28. Adzhubei IA, Schmidt S, Peshkin L, et al. A method and server for predicting damaging missense mutations. Nat Methods. 2010;7(4):248-249.

29. Salgado D, Desvignes J-P, Rai G, et al. UMD-Predictor: A High-Throughput Sequencing Compliant System for Pathogenicity Prediction of any Human cDNA Substitution. Hum Mutat. 2016;37(5):439446.

30. Schwarz JM, Cooper DN, Schuelke M, Seelow D. MutationTaster2: mutation prediction for the deepsequencing age. Nat Methods. 2014;11(4):361-362.

31. Richards S, Aziz N, Bale S, et al. Standards and guidelines for the interpretation of sequence variants: a joint consensus recommendation of the American College of Medical Genetics and Genomics and the Association for Molecular Pathology. Genet Med. 2015;17(5):405-424.

32. Ghosh R, Oak N, Plon SE. Evaluation of in silico algorithms for use with ACMG/AMP clinical variant interpretation guidelines. Genome Biol. 2017;18.

33. Nordang GBN, Busk ØL, Tveten K, et al. Next-generation sequencing of the monogenic obesity genes LEP, LEPR, MC4R, PCSK1 and POMC in a Norwegian cohort of patients with morbid obesity and normal weight controls. Mol Genet Metab. 2017;121(1):51-56.

34. Matthews DR, Hosker JP, Rudenski AS, Naylor BA, Treacher DF, Turner RC. Homeostasis model assessment: insulin resistance and $\beta$-cell function from fasting plasma glucose and insulin concentrations in man. Diabetologia. 1985;28(7):412-419.

35. Ciangura C, Bouillot JL, Lloret-Linares C, et al. Dynamics of change in total and regional body composition after gastric bypass in obese patients. Obesity. 2010;18(4):760-765.

36. Strobel A, Issad T, Camoin L, Ozata M, Strosberg AD. A leptin missense mutation associated with hypogonadism and morbid obesity. Nat Genet. 1998;18(3):213-215.

37. Aslan IR, Ranadive SA, Valle I, Kollipara S, Noble JA, Vaisse C. The melanocortin system and insulin resistance in humans: insights from a patient with complete POMC deficiency and type 1 diabetes mellitus. Int J Obes (Lond). 2014;38(1):148-151.

38. Löffler D, Behrendt S, Creemers JWM, et al. Functional and clinical relevance of novel and known 
PCSK1 variants for childhood obesity and glucose metabolism. Mol Metab. 2017;6(3):295-305.

39. Lubrano-Berthelier C, Cavazos M, Dubern B, et al. Molecular genetics of human obesity-associated MC4R mutations. Ann N Y Acad Sci. 2003;994:49-57.

40. Friedlander Y, Li G, Fornage M, et al. Candidate Molecular Pathway Genes Related to Appetite Regulatory Neural Network, Adipocyte Homeostasis and Obesity: Results from the CARDIA Study. Ann Hum Genet. 2010;74(5):387-398.

41. Nunziata A, Borck G, Funcke J-B, et al. Estimated prevalence of potentially damaging variants in the leptin gene. Mol Cell Pediatr. 2017;4(1):10.

42. Farooqi IS, Wangensteen T, Collins S, et al. Clinical and molecular genetic spectrum of congenital deficiency of the leptin receptor. N Engl J Med. 2007;356(3):237-247.

43. Cooiman MI, Kleinendorst L, Aarts EO, et al. Genetic Obesity and Bariatric Surgery Outcome in 1014 Patients with Morbid Obesity. Obes Surg. 2019.

44. Creemers JWM, Choquet H, Stijnen P, et al. Heterozygous Mutations Causing Partial Prohormone Convertase 1 Deficiency Contribute to Human Obesity. Diabetes. 2012;61(2):383-390.

45. Lubrano-Berthelier C, Dubern B, Lacorte J-M, et al. Melanocortin 4 receptor mutations in a large cohort of severely obese adults: prevalence, functional classification, genotype-phenotype relationship, and lack of association with binge eating. J Clin Endocrinol Metab. 2006;91(5):1811-1818.

46. Ozata M, Ozdemir IC, Licinio J. Human Leptin Deficiency Caused by a Missense Mutation: Multiple Endocrine Defects, Decreased Sympathetic Tone, and Immune System Dysfunction Indicate New Targets for Leptin Action, Greater Central than Peripheral Resistance to the Effects of Leptin, and Spontaneous Correction of Leptin-Mediated Defects. J Clin Endocrinol Metab. 1999;84(10):3686-3695.

47. Krude H, Biebermann H, Schnabel D, et al. Obesity Due to Proopiomelanocortin Deficiency: Three New Cases and Treatment Trials with Thyroid Hormone and ACTH4-10. J Clin Endocrinol Metab. 2003;88(10):4633-4640.

48. Challis BG, Coll AP, Yeo GSH, et al. Mice lacking pro-opiomelanocortin are sensitive to high-fat feeding but respond normally to the acute anorectic effects of peptide-YY3-36. Proc Natl Acad Sci. 2004;101(13):4695-4700.

49. Bomer I, Saure C, Caminiti C, et al. Comparison of energy expenditure, body composition, metabolic disorders, and energy intake between obese children with a history of craniopharyngioma and children with multifactorial obesity. J Pediatr Endocrinol Metab. 2015;28(11-12):1305-1312. 
50. Korsten-Reck U, Kromeyer-Hauschild K, Korsten K, Baumstark MW, Dickhuth HH, Berg A. Frequency of secondary dyslipidemia in obese children. Vasc Health Risk Manag. 2008;4(5):1089-1094.

51. Baron M, Maillet J, Huyvaert M, et al. Loss-of-function mutations in MRAP2 are pathogenic in hyperphagic obesity with hyperglycemia and hypertension. Nat Med. 2019;25(11):1733-1738. 


\section{FIGURE LEGENDS}

Figure 1. Flow chart of subjects included in the study. DNA from patients with severe obesity were sequenced on at least one of the four $L E P, L E P R, P O M C$, and PCSK1 genes. Of 1,486 probands, 126 carried a variant (8.5\%), 100 of whom with heterozygous variant (6.7\%) and 26 with homozygous variant (1.7\%). The clinical phenotyping was conducted in patients followed at Assistance Publique-Hôpitaux de Paris (AP-HP).

Figure 2. Position of the 58 variants identified in LEP, LEPR, POMC, PCSK1 and MC4R genes.

Figure 3. Maximal BMI or BMI Z-score according to the age of obesity onset. Children with (a) heterozygous and homozygous variants, or (b) exclusively heterozygous variants. Adults with (c) heterozygous and homozygous variants, or (d) exclusively heterozygous variants.

The age of obesity onset was defined by age with a BMI above the IOTF 25 curve and by interview for adult patients when the BMI chart was not available. Values are expressed as mean \pm standard deviations. In children, the Spearman correlation was calculated. In adults, groups were compared using the Mann-Whitney test. ${ }^{* *}, \mathrm{p}<.01$; ns, not significant.

Figure 4. Maximal BMI in adults according to the functional impact of variants and zygosity. Values are expressed as mean \pm standard deviations. Groups were compared using the Mann-Whitney test. *, $\mathrm{p}<.05 ;$ ns, not significant.

Figure 5. Comparison of maximal BMI in adults between carriers of heterozygous, combined heterozygous and homozygous variants. Values are expressed as mean \pm standard deviations. Groups were compared using the Mann-Whitney and KruskalWallis tests. ${ }^{* *}, \mathrm{p}<.01 ; \mathrm{ns}$, not significant. 


\section{TABLES}

Table 1. Frequency of variants on $L E P, L E P R, P O M C$ and $P C S K 1$ in patients with severe obesity

\begin{tabular}{|c|c|c|c|c|c|}
\hline Gene & $\begin{array}{l}\text { Number of } \\
\text { patients } \\
\text { with } \\
\text { sequencing } \\
\text { results }\end{array}$ & $\begin{array}{c}\text { Carriers of } \\
\text { homozygous } \\
\text { variants, } \mathbf{n}(\%)\end{array}$ & $\begin{array}{c}\text { Carriers of } \\
\text { homozygous } \\
\text { variants with } \\
\text { moderate to high } \\
\text { predicted } \\
\text { functional impact, } \\
n(\%) \\
\end{array}$ & $\begin{array}{c}\text { Carriers of } \\
\text { heterozygous } \\
\text { variants, } \mathbf{n} \\
(\%)\end{array}$ & $\begin{array}{c}\text { Carriers of } \\
\text { heterozygous } \\
\text { variants with } \\
\text { moderate to high } \\
\text { predicted } \\
\text { functional impact, } \\
n(\%)\end{array}$ \\
\hline LEP & 967 & $3(0.31)$ & $2(0.21)$ & $22(2.3)$ & 0 \\
\hline$L E P R$ & 1,270 & $18(1.4)$ & $18(1.4)$ & 40 (3.1) & (1.8) \\
\hline POMC & 651 & $4(0.61)$ & $1(0.15)$ & $21(3.2)$ & \\
\hline PCSK1 & 366 & $1(0.27)$ & $1(0.27)$ & 27 (7.4) & $5.3)$ \\
\hline Total & 1,486 & $26(1.7)$ & $22(1.5)$ & $100(6.7)$ & $53(3.6)$ \\
\hline
\end{tabular}

Frequencies were calculated based on the number of patients sequenced on LEP, LEPR, POMC, and PCSK1, using direct sequencing and/or next-generation sequencing in a cohort of 1486 probands. After excluding the frequent variant p.Asn221Asp in PCSK1, the frequency of rare heterozygous variants in PCSK1 was $1.4 \%(0.3 \%$ with moderate to high functional impact), and $5.7 \%$ in the four genes $(2.6 \%$ with moderate to high functional impact). 
Table 2. Subjects with combined heterozygous variants

\begin{tabular}{|c|c|c|c|c|c|}
\hline Patients & LEP & $L E P R$ & РОМС & PCSK1 & $M C 4 R$ \\
\hline 1 & p.Val94Met & & & p.Asn221Asp & \\
\hline 2 & & p.Cys99Tyr & & p.Asn221Asp & \\
\hline 3 & & p.Val144Leu & & p.Asn221Asp & \\
\hline 4 & & p.Thr699Met & & p.Asn221Asp & \\
\hline 5 & & p.Ser1014Cys & & p.Asn221Asp & \\
\hline 6 & & & p.Arg89Ser & p.Asn221Asp & \\
\hline 7 & & & p.Tyr221Cys & p.Asn221Asp & \\
\hline 8 & p.Val94Met & & p.Asp53Gly & & \\
\hline 9 & p.Val94Met & p.Thr699Met & & & \\
\hline 10 & & & p.Asp53Gly & c. $1196+6 \mathrm{del}$ & \\
\hline 11 and 12 & & p.Thr699Met & & & er58c \\
\hline
\end{tabular}

Combined heterozygous variants are defined as two heterozygous variants on two different genes of the leptin-melanocortin pathway. Patients 11 and 12 are sisters. 
Table 3. Annotation of the 58 variants carried by the 126 probands

\begin{tabular}{|c|c|c|c|c|c|}
\hline Variant & Allele frequency & Consequence & Domain & Zygosity & Functional impact \\
\hline \multicolumn{6}{|l|}{ LEP } \\
\hline p.Gln $55^{*}$ & & Nonsense & Exon 2 & Homozygous & High \\
\hline p.Arg105Trp a & & Missense & Exon 3 & Homozygous & High \\
\hline p.Tyr18Cys & 0.0003606 & Missense & Exon 2 & Heterozygous & Low \\
\hline p.Ile45Val c & 0.00007070 & Missense & Exon 2 & Heterozygous & Low \\
\hline p.Val94Met ${ }^{c}$ & 0.008404 & Missense & Exon 2 & Homozygous, heterozygous & Low \\
\hline p.Val94Leu c & & Missense & Exon 2 & Heterozygous & Low \\
\hline \multicolumn{6}{|l|}{ LEPR } \\
\hline c. $2597+1 G>A^{b}$ & & Splice donor & Fibronectin III & Homozygous & High \\
\hline p.Lys204Arg & 0.0001878 & Missense & CRH I & Heterozygous & Low \\
\hline p.Tyr1079del & 0.00001420 & Inframe deletion & Cytoplasmic & Heterozygous & Unknown \\
\hline p.Arg282_Glu283delinsLys c & & Inframe indel & CRH I & Heterozygous & Unknown \\
\hline p.Ser389Asn & 0.00003583 & Missense & Ig-like & Heterozygous & High \\
\hline p.Tyr $422 \mathrm{His}^{\mathrm{b}}$ & & Missense & CRH II & Compound heterozygous & Moderate \\
\hline p.Arg448Thr & 0.00002476 & Missense & CRH II & Heterozygous & Moderate \\
\hline p.Trp449Leu ${ }^{c}$ & 0.000003979 & Missense & CRH II & Heterozygous & Moderate \\
\hline p.Gln491Pro & & Missense & CRH II & Heterozygous & Moderate \\
\hline p.Pro540Thr c & 0.00001419 & Missense & CRH II & Heterozygous & Moderate \\
\hline p.Glu644Asp ${ }^{c}$ & 0.00001992 & Missense & Fibronectin III & Heterozygous & Low \\
\hline p.Thr699Metc & 0.003387 & Missense & Fibronectin III & Heterozygous & Moderate \\
\hline p.Thr730Ala c & 0.000007960 & Missense & Fibronectin III & Heterozygous & Moderate \\
\hline p.Val220Ile c & 0.0001630 & Missense & CRH I & Heterozygous & Low \\
\hline p.Leu372Ser & & Missense & Ig-like & Compound heterozygous & Moderate \\
\hline p.Pro166Cysfs*7 b & & Frameshift & $\mathrm{CRH}$ I & $\begin{array}{l}\text { Homozygous, compound } \\
\text { heterozygous }\end{array}$ & High \\
\hline
\end{tabular}




\begin{tabular}{|c|c|c|c|c|c|}
\hline \multirow{2}{*}{\multicolumn{6}{|c|}{ Comnound hetorozurous }} \\
\hline & & Splice acceptor & CRH II & Compound heterozygous & High \\
\hline p.Cys604Gly & & Missense & CRH II & Homozygous & Moderate \\
\hline p.Asn624Lysfs*21 b & & Frameshift & CRH II & Homozygous & High \\
\hline p.Thr711Asnfs*18b & & Frameshift & Fibronectin III & Compound heterozygous & High \\
\hline p.Leu786Pro ${ }^{b}$ & 0.000003996 & Missense & Fibronectin III & Homozygous & Moderate \\
\hline p.His800_Asn831del & & Splice donor & Fibronectin III & Homozygous & High \\
\hline p.Pro876Leu & 0.000007075 & Missense & Cytoplasmic & Compound heterozygous & High \\
\hline p.Ile900Val c & 0.0008664 & Missense & Cytoplasmic & Heterozygous & Low \\
\hline p.Glu977* & & Nonsense & Cytoplasmic & Homozygous & High \\
\hline p.Ser1014Cys & 0.0007183 & Missense & Cytoplasmic & Heterozygous & Low \\
\hline p.Thr1083Ala ${ }^{c}$ & 0.0001948 & Missense & Cytoplasmic & Heterozygous & Low \\
\hline p.Asp124Glyc & 0.0007144 & Missense & CRH I & Heterozygous & Low \\
\hline p.Met1? & 0.000003980 & Start lost & & Homozygous & High \\
\hline p.Val144Leu ${ }^{c}$ & 0.0001447 & Missense & CRH I & Heterozygous & Low \\
\hline p.Ser289Leu & 0.00002123 & Missense & CRH I & Heterozygous & Low \\
\hline \multicolumn{6}{|l|}{ POMC } \\
\hline p.Arg236Gly a & 77 & Missense & $\begin{array}{l}\text { Cleavage site } \beta \text { - } \\
\mathrm{MSH} / \beta \text {-endorphin }\end{array}$ & Heterozygous & High \\
\hline c. $-11 \mathrm{C}>\mathrm{A}^{\text {a c }}$ & 0.00002838 & $\begin{array}{l}\text { Premature start codon } \\
\text { gain }\end{array}$ & & Heterozygous & High \\
\hline p.Arg89Ser & & Missense & $\mathrm{\gamma}$-MSH & Heterozygous & Moderate \\
\hline p.Met223Thr & 0.00004966 & Missense & $\beta$-MSH & Heterozygous & Moderate \\
\hline p.Asp53Gly bc & 0.001007 & Missense & N-terminal & Homozygous, heterozygous & Low \\
\hline p.Phe87Leuc & 0.001111 & Missense & $\mathrm{\gamma}$-MSH & Heterozygous & Moderate \\
\hline p.Leu209Pro ${ }^{c}$ & 0.00005656 & Missense & $\mathrm{\gamma}$-LPH & Heterozygous & Low \\
\hline p.Glu214Gly b c & 0.005743 & Missense & $\beta$-MSH & Homozygous, heterozygous & Low \\
\hline p.Tyr221Cys ac & 0.0008272 & Missense & $\beta$-MSH & Heterozygous & High \\
\hline p.Trp228Ser ${ }^{c}$ & 0.00001595 & Missense & $\beta$-MSH & Heterozygous & High \\
\hline p.Arg75fs*119b & & Frameshift & $\mathrm{\gamma}$-MSH & Homozygous & High \\
\hline p.Ala195Thr & 0.0007578 & Missense & $\gamma-\mathrm{LPH}$ & Heterozygous & Low \\
\hline \multicolumn{6}{|l|}{ PCSK1 } \\
\hline c. $1196+6$ del $^{c}$ & 0.00001418 & Splice region & Intron & Heterozygous & Unknown \\
\hline p.Asn221Asp a c & 0.03810 & Missense & Catalytic & Heterozygous & Moderate \\
\hline p.Ser24Metfs*73 c & 0.000007953 & Frameshift & Signal peptide & Heterozygous & High \\
\hline
\end{tabular}




\begin{tabular}{|c|c|c|c|c|c|}
\hline $\begin{array}{l}\text { c.286-2A }>G^{b} \\
\text { p.Leu22Pro } \\
\end{array}$ & 0.0001414 & $\begin{array}{l}\text { Splice acceptor } \\
\text { Missense }\end{array}$ & $\begin{array}{l}\text { Propeptide } \\
\text { Signal peptide }\end{array}$ & $\begin{array}{l}\text { Homozygous } \\
\text { Heterozygous }\end{array}$ & $\begin{array}{l}\text { High } \\
\text { Low }\end{array}$ \\
\hline $\begin{array}{l}\text { MC4R } \\
\text { p.Ser58Cys }{ }^{c}\end{array}$ & & Missense & Transmembrane & Heterozygous & High \\
\hline
\end{tabular}

a Functional assay available

b Phenotype available for the variant in homozygous or compound heterozygous state

c Phenotype available for the variant in heterozygous state

The allele frequency was determined from GnomAD (Genome Aggregation Database). Some have not been reported.

Abbreviations: CRH, cytokine receptor homology; Ig, immunoglobulin; MSH, melanocyte stimulating hormone 


\begin{tabular}{|c|c|c|c|c|c|c|c|c|c|c|}
\hline & \multicolumn{5}{|c|}{ CHILDREN } & \multicolumn{5}{|c|}{ ADULTS } \\
\hline & Homozygous & $\mathrm{n}=4$ & Heterozygous & $\mathrm{n}=29$ & $\mathrm{p}$ value & Homozygous & $\mathrm{n}=12$ & Heterozygous & $\mathrm{n}=31$ & $\mathrm{p}$ value \\
\hline Female gender, n (\%) & $2(50)$ & & $11(38)$ & & NS & $9(75)$ & & $19(61)$ & & NS \\
\hline Age at phenotyping, years & $11.8 \pm 6.5$ & & $11.2 \pm 6$ & & NS & $30.7 \pm 9.6$ & & $31.1 \pm 9.6$ & & NS \\
\hline Age at maximal BMI, years & $8.6 \pm 6.1$ & & $10.8 \pm 5.8$ & & NS & $25.7 \pm 9.8$ & & $29.5 \pm 9.5$ & & NS \\
\hline \multicolumn{11}{|l|}{$\begin{array}{l}\text { Weight history and body } \\
\text { composition }\end{array}$} \\
\hline Maximal BMI Z-score in children & $7.2 \pm 3.5$ & & $6.0 \pm 1.7$ & 29 & NS & & & & & \\
\hline Maximal BMI in adults, $\mathrm{kg} / \mathrm{m}^{2}$ & & & & & & $65.9 \pm 15.7$ & 12 & $53 \pm 13.3$ & 31 & .015 \\
\hline $\begin{array}{l}\text { Onset of obesity }<6 \text { years of age, } n \\
(\%)\end{array}$ & $4(100)$ & & $28(97)$ & 29 & NS & $11(92)$ & 12 & $15(52)$ & 29 & .03 \\
\hline Age of obesity onset, years & $0.6 \pm 0.8$ & & $1.5 \pm 1.3$ & 28 & NS & $0.4 \pm 0.2$ & 11 & $5.4 \pm 4.3$ & 13 & $<.001$ \\
\hline Parental overweight, n (\%) & $3(75)$ & & $25(89)$ & 28 & NS & $7(58)$ & 12 & $26(84)$ & 31 & NS \\
\hline Parental obesity, n (\%) & 0 & & $17(61)$ & 28 & .04 & $5(42)$ & 12 & $21(68)$ & 31 & NS \\
\hline Body fat, $\%$ & ND & & ND & & & $51 \pm 5.3$ & 11 & $47 \pm 6.3$ & 25 & .08 \\
\hline Trunk fat mass, $\%$ & ND & & ND & & & $44.3 \pm 3.1$ & 11 & $47.7 \pm 4.91$ & 22 & .048 \\
\hline Measured REE (kcal/24h) & ND & & ND & & & $2318 \pm 334$ & 11 & $2337 \pm 623$ & 27 & NS \\
\hline \multicolumn{11}{|l|}{ Associated phenotype } \\
\hline Hyperphagia, n (\%) & $4(100)$ & & $25(86)$ & 29 & NS & $12(100)$ & 12 & $28(90)$ & 31 & NS \\
\hline Food impulsivity, n (\%) & $3(75)$ & & $4(14)$ & 29 & .02 & $10(83)$ & 12 & $13(42)$ & 31 & .04 \\
\hline$\geq 1$ central endocrine deficiency, $n$ & $2(50)$ & & $1(3)$ & 29 & .03 & $9(75)$ & 12 & $8(26)$ & 31 & $<.01$ \\
\hline (\%) & 0 & & 1 & & & 7 & & 6 & & \\
\hline Hypogonadism, $\mathrm{n}$ & 1 & & 0 & & & 6 & & 2 & & \\
\hline GH deficiency, $\mathrm{n}$ & 0 & & 0 & & & 3 & & 0 & & \\
\hline Hypothyroidism, $\mathrm{n}$ & 1 & & 0 & & & 2 & & 1 & & \\
\hline ACTH deficiency, $\mathrm{n}$ & 1 & & 0 & & & 0 & & 1 & & \\
\hline Diabetes insipidus, $\mathrm{n}$ & & & & & & & & & & \\
\hline
\end{tabular}




\begin{tabular}{|c|c|c|c|c|c|c|c|c|c|}
\hline $\begin{array}{l}\text { Ratio leptin }(\mathrm{ng} / \mathrm{ml}) \text { / fat mass }(\mathrm{kg}) \\
\text { Developmental delay, } \mathrm{n}(\%)\end{array}$ & $\begin{array}{l}\mathrm{ND} \\
1(25)\end{array}$ & $\begin{array}{l}\text { ND } \\
7(24)\end{array}$ & 29 & NS & $\begin{array}{c}1.9 \pm 2.3 \\
4(33)\end{array}$ & $\begin{array}{l}10 \\
12\end{array}$ & $\begin{array}{c}1.1 \pm 0.6 \\
6(19)\end{array}$ & $\begin{array}{l}20 \\
31\end{array}$ & $\begin{array}{l}\text { NS } \\
\text { NS }\end{array}$ \\
\hline OSA, n (\%) & $1(25)$ & & 29 & NS & $6(50)$ & 12 & $18(58)$ & 31 & NS \\
\hline HOMA-IR, n (\%) & $2(50)$ & $15(56)$ & 27 & NS & $3(25)$ & 12 & $17(61)$ & 28 & .084 \\
\hline Dyslipidemia, n (\%) & $1(25)$ & $4(15)$ & 27 & NS & $2(17)$ & 12 & $12(39)$ & 31 & NS \\
\hline Arterial hypertension, n (\%) & 0 & $2(7)$ & 29 & NS & 0 & 12 & $10(32)$ & 31 & .04 \\
\hline
\end{tabular}

Arterial hypertension, $\mathrm{n}(\%)$

$2(7)$

NS

.04

Values are expressed as mean \pm standard deviations and number (percentage). The Mann-Whitney test was used to compare quantitative variables between subjects with heterozygous and homozygous
variants. Qualitative variables were tested with the Chi-square test or Fisher's exact test when appropriate. The "heterozygous" group is comprised of carriers of single heterozygous variants and combined heterozygous variants. Abbreviations: ACTH, adrenocorticotropin; BMI, body mass index; GH, growth hormone; HOMA-IR, Homeostasis Model Assessment of Insulin Resistance; ND, not determined; NS, not significant; OSA, obstructive sleep apnea; REE, resting energy expenditure. 
Table 5. Central endocrine deficiencies in carriers of homozygous and heterozygous variants

\begin{tabular}{|c|c|c|c|c|c|c|c|c|}
\hline & \multicolumn{3}{|c|}{$\begin{array}{c}\begin{array}{c}\text { Carriers of homozygous variants (n } \\
=16)\end{array} \\
\end{array}$} & \multicolumn{5}{|c|}{ Carriers of heterozygous variants $(n=60)$} \\
\hline & $\begin{array}{l}\boldsymbol{L E P R} \\
\mathrm{n}=12\end{array}$ & $\begin{array}{c}P O M C \\
\mathrm{n}=3\end{array}$ & $\begin{array}{l}\text { PCSK1 } \\
\mathrm{n}=1\end{array}$ & $\begin{array}{c}\boldsymbol{L E P} \\
\mathrm{n}= \\
11\end{array}$ & $\begin{array}{l}\boldsymbol{L E P R} \\
\mathrm{n}=30\end{array}$ & $\begin{array}{c}\text { POMC } \\
\mathrm{n}=10\end{array}$ & $\begin{array}{c}\text { PCSK1 } \\
\mathrm{n}=11\end{array}$ & $\begin{array}{c}\text { POMC + } \\
\text { PCSK1 } \\
\mathrm{n}=2\end{array}$ \\
\hline Hypogonadism, n (\%) & $6(50)$ & 1 & 0 & $1(9)$ & $4(13)$ & 0 & 0 & 2 \\
\hline GH deficiency, n (\%) & $6(50)$ & 1 & 0 & 0 & 0 & 0 & 1 & 1 \\
\hline $\begin{array}{l}\text { Hypothyroidism, n } \\
(\%)\end{array}$ & $2(17)$ & 1 & 0 & 0 & 0 & 0 & 0 & 0 \\
\hline $\begin{array}{l}\text { ACTH deficiency, } \mathrm{n} \\
(\%)\end{array}$ & $1(8)$ & 1 & 1 & 0 & 0 & 0 & 0 & 1 \\
\hline $\begin{array}{l}\text { Diabetes insipidus, } \mathrm{n} \\
(\%)\end{array}$ & 0 & 0 & 1 & 0 & 0 & 0 & 1 & 0 \\
\hline
\end{tabular}


Figure 1

6467 individuals with sequencing
results on $L P$, LEPP, POMC, PCSK 1
Gad and or MCAB
$(71 \%$ adults

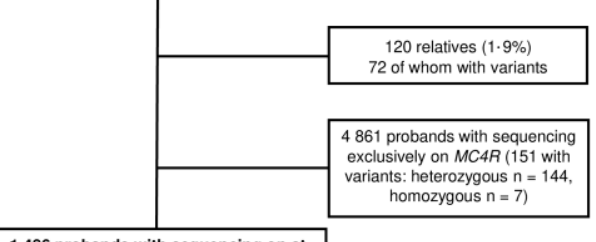

1486 probands with sequencing on at
least one of the tour $\angle P P$, LEPR, POMC

and PCSK genes
(600\% aduts)

126 probands with variants
$(40 \%$ adults

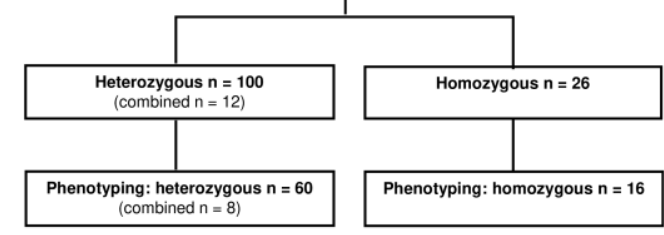


LEPR

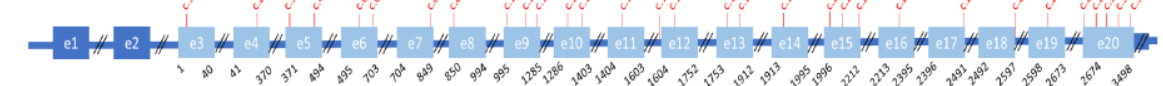

LEP $\left.3^{5}\right)^{\circ}$

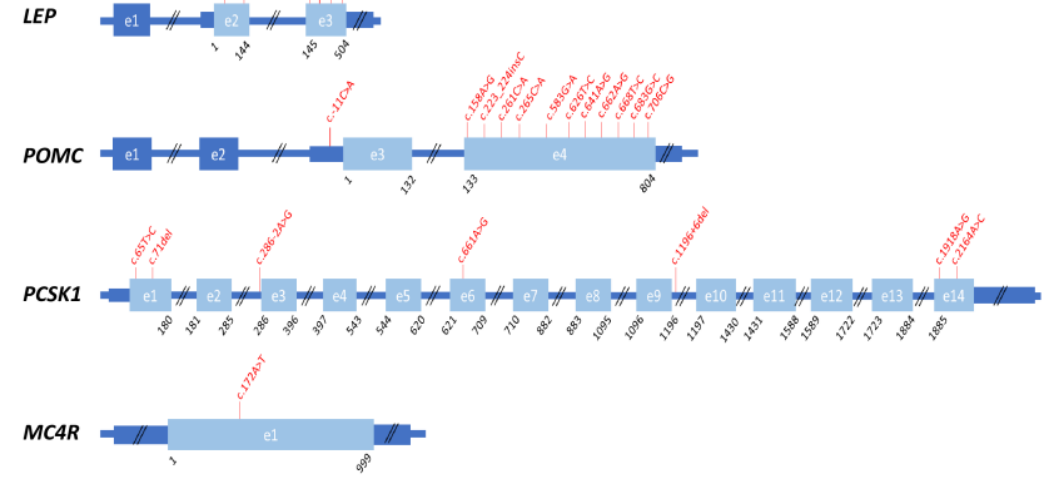


Figure 3

(b)
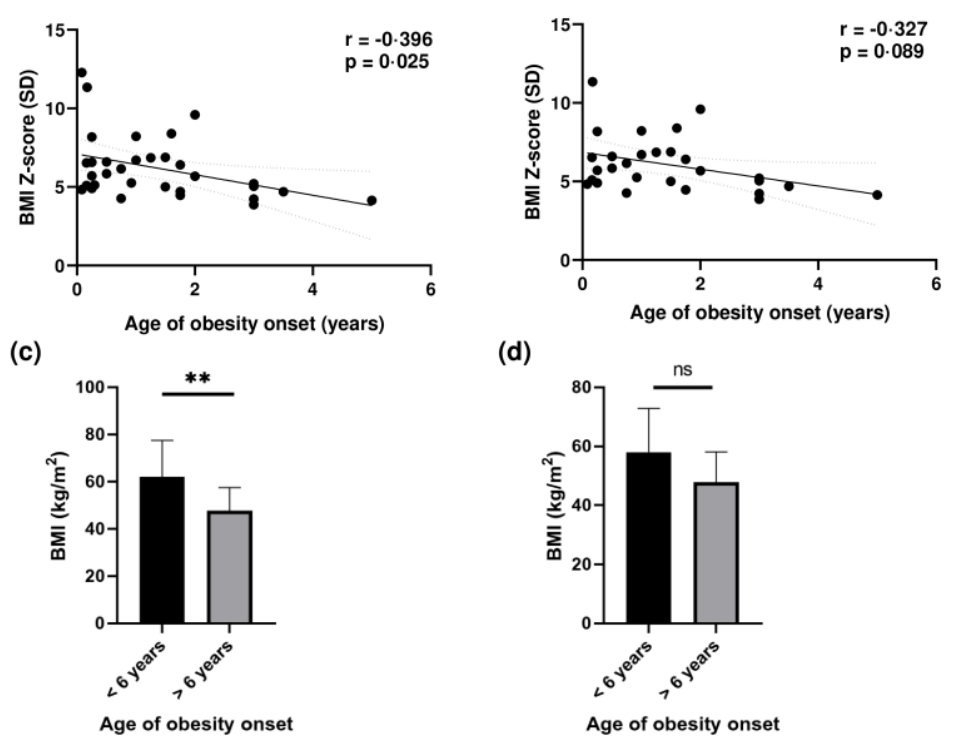

(d)

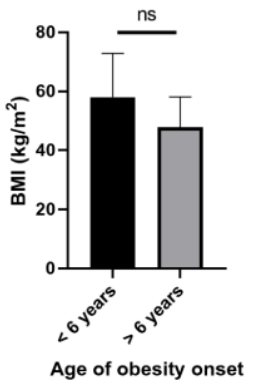


Figure 4

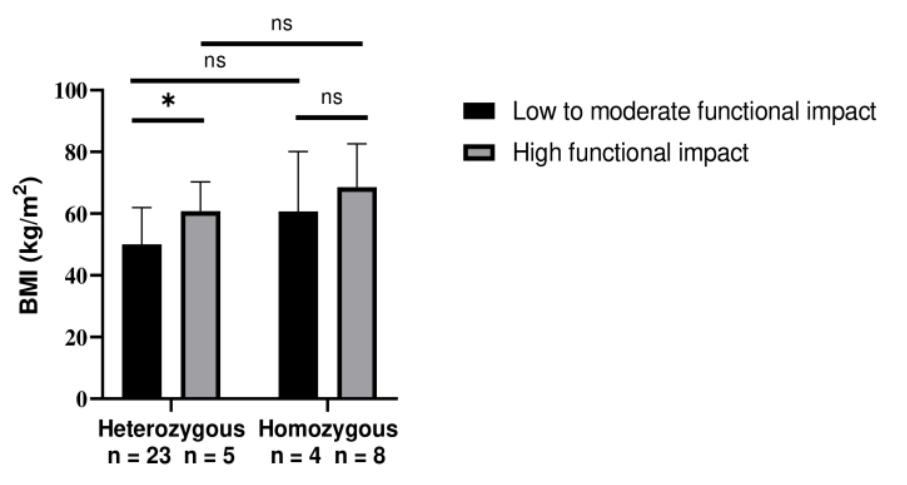


Figure 5

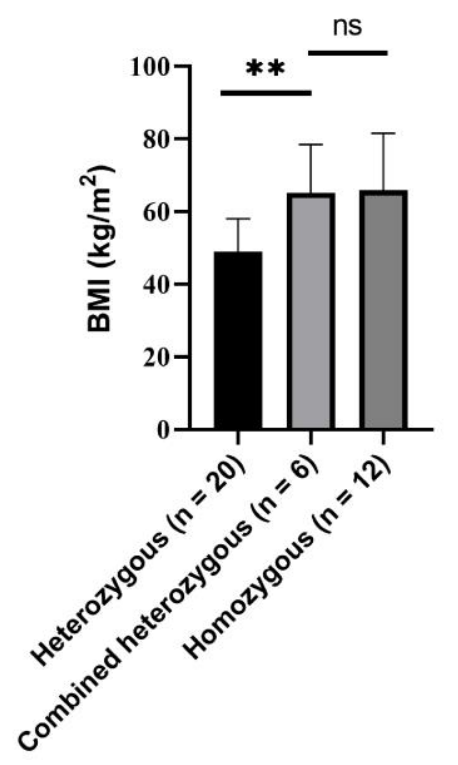

